\title{
Polémica en tres tiempos. Debates Alrededor DE LA SAGA NACIONAL DE BEATRIZ GUIDO*
}

\section{Marcos Zangrandi ${ }^{* *}$}

\section{Resumen}

Este artículo estudia las novelas de la llamada "saga nacional" de la escritora argentina Beatriz Guido en relación con los debates intelectuales que se produjeron en las décadas de 1950 y 1960 en este país. Con este fin, el texto repasa las críticas relevantes que obtuvieron Fin de fiesta (1958), El incendio y las vísperas (1964) y Escándalos y soledades (1970). Esas recepciones permiten ver, por un lado, los ejes de discusión políticos y culturales de estos años, desde la exigencia de compromiso y de toma de contacto con la realidad hasta la urgencia de la acción que se impone en la puerta de los años 1970. Las críticas ponen de manifiesto, asimismo, la sintonía entre política y literatura en la que participa activamente Guido. Finalmente, los debates muestran los cambios en el campo intelectual argentino provocados tanto por la presencia del peronismo como por las expectativas revolucionarias que se suscitaron durante estas décadas.

Palabras clave: Literatura argentina, Beatriz Guido, peronismo, realismo, compromiso.

\section{Polemic in three times. Debates around BeAtriz GUIDO'S SAGA NACIONAL}

\begin{abstract}
This paper examines the argentine writer Beatriz Guido's novels (known as saga nacional) in relationship with intellectual debates of the 1950s and 1960s. To this end, this text analyses the relevant reviews that obtained Fin de fiesta (1958), El incendio y las vísperas (1964) and Escándalos y soledades (1970). These dialogues allow us to see, first, the axes of political and cultural discussion of these years, from the requirement of commitment and making contact with reality to the urgency of action that imposes on the door of the 1970s. The reviews show also the congruence between politics and literature where actively participated Guido's literature. Finally, the reviews show the changes in the Argentine intellectual field caused both by the presence of Peronism and revolutionary expectations that were raised during these decades.
\end{abstract}

Keywords: Argentine literature, Beatriz Guido, Peronism, realism, commitment.

Recibido: 09-07-2015

Aceptado: 02-09-2015

* Este artículo está adscripto en el proyecto colectivo "Lectura, lectores y escritores en Argentina" (UBACyT C012 2012-2015) financiado por la Secretaría de Ciencia y Técnica de la Universidad de Buenos Aires.

** Argentino. Doctor en Ciencias Sociales, Universidad de Buenos Aires. Magíster en Comunicación y Cultura, Universidad de Buenos Aires. Pertenece a al Instituto de Literatura Hispanoamericana de la Universidad de Buenos Aires y al Consejo Nacional de Investigaciones Científicas y Técnicas (CONICET). marcoszangrandi@gmail.com 


\section{Introducción}

El transcurso de la década de 1950 imprimió un giro en el campo literario argentino. La hegemonía de una cultura letrada y encapsulada dio lugar progresivamente a un nuevo escenario, poroso, problemático y vinculado al debate político y social (Terán, 1991; Sarlo, 2007; Zangrandi, 2016) ${ }^{1}$. Las revistas Contorno, Las ciento y una, Ciudad, y, más adelante, Hoy en la cultura, entre algunas otras, fueron las que pusieron de manifiesto ese cambio que ubicaba al escritor en un escenario de discusiones y de debates frente a un vertiginoso marco de transformaciones.

Este giro respondía a varios factores. Entre los más importantes, a la nueva figura que adquirió el intelectual, cuya dimensión no podía despegarse tanto del mundo problemático que dejó la Segunda Guerra Mundial como de las expectativas de la Revolución que se generaron hacia el final de esta década. En el caso particular de Argentina, la alteración del campo cultural fue, además, catalizada por la experiencia de surgimiento del peronismo. Su presencia, tanto cuando gobernó el país (1946-1955), como luego de que fuera desalojado del poder, marcó el pulso de la agenda cultural e invocó nuevas perspectivas sobre la relación entre el escritor y el mundo.

El peronismo se reveló, en este sentido, inexcusable para quien se proponía escribir: empujó a tomar posición a todo el arco intelectual. El escenario se polarizó: los agrupados en Sur, La Nación, la Sociedad Argentina de Escritores y en otros núcleos, enfrentaron con vehemencia a un peronismo visto como un régimen autoritario cuyo reflejo era un simulacro o una fachada continua (entre otros Jorge L. Borges, Silvina y Victoria Ocampo, Julio Cortázar, Manuel Mujica Lainez, Ernesto Sábato, Ezequiel Martínez Estrada, entre otros) $)^{2}$. Desde un espacio opuesto, otros intelectuales, con sus matices, veían en la figura de Perón un horizonte de defensa de los intereses nacionales y de cierta armonía social orgánica (entre ellos Arturo Cancela, Leopoldo Marechal, Horacio Rega Molina,

1 Por supuesto que este pasaje posee matices. Si bien es cierto que la revista Sur era representativa de la primera tendencia, también es cierto que la publicación de Victoria Ocampo fue pionera en introducir hacia finales de la década de 1940 algunos debates políticos-sociales que la alejaban de una línea cultural aséptica.

2 El artículo "L'illusion comique" (1955) de Borges es ejemplar de la retórica del simulacro asociada con el peronismo. Sobre los debates acerca de los intelectuales y el fenómeno peronista, ver el análisis de Beatriz Sarlo en La batalla de las ideas (2007). 
José María Castiñeira de Dios, César Tiempo y Manuel Gálvez). Sólo años después del golpe de Estado de setiembre de 1955 y la proscripción del peronismo, comenzarían a formarse nuevas lecturas y nuevos debates alrededor del movimiento popular y a sus líderes, relacionadas sobre todo con la movilización y la justicia social (Sarlo, 2007; Korn, 2007). Se trataba no sólo de un cambio político que movía los cimientos con que se había construido el país. El peronismo, de acuerdo a las bases sociales que convocaba y a su modalidad política, cuestionaba el lugar y el modo de producir la cultura. La emergencia ineludible de la problemática social interpelaba a los escritores a cuestionarse el lugar de la literatura en un mundo en cambio, consolidándose esta línea de pensamiento luego de que en 1959 triunfara la revolución en Cuba y, con ello, se fortaleciera el horizonte de transformación sociopolítica en el continente.

La narrativa de Beatriz Guido (1922-1988) emerge y se inscribe en este marco de debates políticos y culturales que se intensificaría durante los años 1960. Con una posición socialdemócrata y vinculada inicialmente a los circuitos consagrados (Sur y La Nación) y luego a sectores culturales modernizadores (en particular al cine), su figura intelectual se construyó polemizando continuamente con todos los frentes intelectuales. Sus novelas de la llamada saga nacional -Fin de fiesta (1958), El incendio y las vísperas (1964) y Escándalos y soledades (1970) -, en las que contaba episodios contemporáneos de la vida política argentina, fueron materia de fuerte debate y muestran la intensidad de las disputas simbólicas de aquellos años. Cada una de ellas obtuvo variados comentarios; pero más aún, cada una de ellas se transformó en un pivote de los debates coyunturales. Desde las filas del peronismo, fueron objetadas vehementemente por su condición de opositora encarnizada. Desde la izquierda, Guido encontró duras impugnaciones; entre ellas, las que la sindicaban como una abanderada de los ideales de un socialismo idealista y anacrónico. La particularidad las polémicas alrededor de la saga es la capacidad de mostrar la dimensión que tuvo cierta literatura en esta época. Estas novelas no sólo invocaron interpretaciones a partir de determinado montaje simbólico, sino que, dada su manifiesta escenificación de sucesos históricos recientes cuyo sentido se encontraba bajo discusión, ponía a la literatura en el centro de las disputas políticas y culturales. Todavía resultan sorprendentes, en este sentido, la felicitación de Frondizi en la ocasión de la aparición de Fin de fiesta y la respuesta 
de Perón respecto de El incendio y las vísperas, lo que descubre una imbricación inédita que transformaba a escritores en agentes políticos y a presidentes en críticos literarios.

Beatriz Guido nació en Rosario en 1922. Su madre, la actriz uruguaya Bertha Eirin, y su padre, el célebre arquitecto Ángel Guido, eran amigos de pintores, escritores y pensadores latinoamericanos afamados, por lo que, de niña, Beatriz tuvo contacto con artistas tales como Salvadora Medina Onrubia, Leopoldo Lugones, David Alfaro Siqueiros, Ricardo Rojas, José Ortega y Gasset y Gabriela Mistral, entre otros-. Siendo joven, Beatriz Guido viajó a Roma y París para estudiar con intelectuales de primera línea. Sin embargo, volvió a la Argentina para dedicarse a escribir. Su primer libro, Regreso a los hilos, fue publicado en 1947; no obstante, su carrera no tomó impulso hasta que a fines de 1954 la novela La casa del ángel obtuvo el primer premio de Emecé (Osorio, 1991; Mucci, 2002). Para entonces ya había conocido al director de cine Leopoldo Torre Nilsson, con quien, además de su pareja, conformó una dupla sinérgica de labor y colaboración entre cine y literatura. Más aún, durante los años 1950 y parte de la década siguiente, la escritora y el cineasta se convirtieron en usina modernizadora de la cultura argentina: sus propuestas marcaban la contemporaneidad del cine, la literatura y el pensamiento.

¿Cuáles son los hilos conductores de la saga nacional? Las ficciones redundan sobre familias en proceso de ruptura y disolución vinculadas en distintos aspectos con un suceso o proceso político de la historia reciente. Sobre cada escenario político están presentes continuamente las figuras de Perón y del peronismo y, contiguamente, la idea de un país alterado. Perón es la voz del 17 de octubre en las radios que suena en las calles solitarias del sur porteño (Fin de fiesta); el tirano que motiva la expropiación, el fuego y la castración (El incendio y las vísperas); el referente exiliado que negocia el futuro político argentino (Escándalos y soledades) ${ }^{3}$. Con esta figura, más o menos presente, la república parece degradada definitivamente y perdida del curso progresista y liberal que adquirió en las primeras décadas del siglo XX.

3 En mi libro Familias póstumas (2016) muestro que las variadas ficciones argentinas sobre familias rotas durante el periodo 1953-1963 resultan de una lectura alegórica de profundas rupturas en el orden político y cultural sucedidas luego de 1945. 


\section{Fin de fiesta y el debate sobre la realidad}

El ascenso a la presidencia del radical intransigente Arturo Frondizi en 1958 -pacto secreto con Perón mediante- fue visto con agrado por una buena parte del arco político, ya que percibía en él una posibilidad de síntesis entre el proyecto popular y una perspectiva republicana. Con Frondizi parecía emerger un país que después de integrar a los sectores obreros se levantaba para desarrollarse sin la presencia de Perón. La propuesta de Frondizi parecía iniciar una etapa optimista que daba lugar a un proyecto de integración social y de modernización. Poco tiempo pasó para que estas convicciones se derrumbaran frente al juego de presiones militares, corporativas y políticas que enfrentó el gobierno (cf. James, 2007).

La publicación de Fin de fiesta coincidió con el ascenso efectivo de Arturo Frondizi. La novela, contada desde el mundo personal de un adolescente, recorría las prácticas caudillistas, cuyos modos se repetían en los hábitos familiares (o, desde otro punto de vista, el hábito político tenía sustento en el orden privado). La figura central es Braceras, caudillo conservador del conurbano sur de Buenos Aires durante la década de 1930, que vive con sus cuatro nietos. La narración se enfoca en el adolescente Adolfo Peña Braceras, quien crece entre la violencia brutal de las bandas de gánsteres, la crueldad vital del campo, los burdeles de la Isla Maciel y la educación que imparten los curas. El personaje de Braceras era alusivo de Alberto Barceló, intendente de Avellaneda en varias oportunidades y legislador nacional durante aquellos años, que recurrió a todo tipo de prácticas fraudulentas y delictivas durante su larga carrera política.

Por su contenido alegórico y su impronta polémica, las páginas finales de Fin de fiesta son particularmente sugestivas. Braceras muere, pero tanto en su velatorio como en su entierro sólo un puñado asiste (la familia más próxima y algunos protegidos que mantienen un último gesto de fidelidad). El caudillo ha perdido a su pueblo. Ha perdido la calle. ¿Dónde están todos aquellos que durante años vitoreaban y aplaudían cada acción de Braceras? Las casas y las calzadas parecen estar vacías. Los nietos escuchan por radio: han ido a plaza de Mayo a rescatar a un coronel, un día de octubre de 1945. Sin escribir nunca su nombre, Beatriz Guido estaba señalando que el sistema político corrupto y violento no moría, se transmutaba en la figura de Juan D. Perón. 
Fin de fiesta coincidía con el clima político y cultural de aquella época. Con su apuesta de intervención política y de intervención sobre sucesos en estado de discusión, Guido se acercaba a la hegemonía del realismo que se apoderó de la literatura argentina en el paso de la década de 1950 a la de 1960, potenciada por la premisa, cada vez más presente, del compromiso del escritor con su realidad. Efectivamente, la óptica realista como eje de análisis se reitera en los ensayos más importantes del periodo. El realismo, en sus distintas variantes, fue la línea estética que atravesó toda la época y a la que los escritores apelaron o rechazaron, pero no pudieron dejar de advertir. La búsqueda de un lenguaje mimético, la escenificación del conflicto social, la actualidad problemática de los temas y la utilización de técnicas narrativas que quebrasen las estructuras clásicas (y ello llevó, en ciertos casos, a la experimentación formal), fueron centrales en estos años.

Bajo esta perspectiva, Beatriz Guido empezaba a participar de una nueva dimensión que adquiría la literatura, ligada irrevocablemente a los debates públicos. Tanto fue así que el presidente Frondizi le envió una carta para felicitarla por Fin de fiesta. "Su tema" -le escribía el mandatario-,

tan estrechamente ligado a aspectos esenciales de la realidad argentina contemporánea, como también la profundidad de su enfoque humano y la excelente técnica narrativa, me han puesto en contacto con una destacable producción de la novelística actual de nuestro país. Permítame felicitarla por su obra y alentarla a proseguir ahondando en la realidad de nuestro país, que todos necesitamos conocer y comprender para poder alcanzar la superación que anhelamos. (cit. en Guido, ¿Quién le teme a mis temas? 372$)^{4}$

La intervención personal de un presidente en ejercicio sobre una obra literaria marca que la literatura adquiría un alcance político significativo.

La actualidad de la novela de Guido y la profundización de la realidad que destaca Frondizi no eran extrañas en la crítica de esos años. El crítico Noé Jitrik (1959) señalaba en Seis novelistas argentinos de la nueva promoción nuevas prácticas y novedosas perspectivas de 
toda una camada de escritores jóvenes, en la que incluía a Guido ${ }^{5}$. Esta generación de escritores se definía por algunos rasgos comunes: la toma de posición, la temática, los procedimientos formales innovadores. Su variada producción se caracteriza por la "responsabilidad" (aspecto que remitía al Sartre (1959) de ¿Qué es la literatura?), en tanto que intervención a través de la palabra. Estos narradores querían "convocar alrededor de su tarea la posibilidad máxima de acción, como si sintiera que la pasividad del libro que espera al lector deba trocarse por los juicios que se toma, en acción transformadora revolucionaria" (26). La obra literaria era un objeto que provoca al lector a participar en el debate, un movilizador de la conciencia. Todo esto, reconocía el crítico, era producto de la experiencia peronista. Ese pasado ineludible ofreció a los jóvenes escritores el conocimiento de la emergencia social, pero no les escamoteaba el proyecto promisorio que ofrecía el presente. Fin de fiesta, así, ponía de manifiesto el encuentro de la subjetividad con la "realidad", que sólo podía emerger como un encuentro traumático. De allí que esta novela fuese para Jitrik superior a las anteriores. Beatriz Guido no se quedaba en la inquisitiva de la subjetividad (como había sucedido en las novelas anteriores La casa del ángel [1955] y La caída [1956]). Decidía, en cambio, narrar e intervenir en sucesos históricos contemporáneos, entrar en la polémica. Se puede observar hasta qué punto la recepción de Jitrik condensa la aspiración de cambio político y el espíritu cultural posperonista con su lectura de Fin de fiesta.

El sociólogo y crítico Juan Carlos Portantiero discrepaba, en cambio, con tal compromiso de la novela, marcando además los límites del proyecto frondicista respecto de la izquierda renovada. En el ensayo Realismo y realidad en la narrativa argentina (1961) comparaba Fin de fiesta con la novela Los dueños de la tierra de David Viñas editada el mismo año (1958). Mientras que esta narración abría un diálogo profundo con el problema social, Guido parecía extraviada en los psicologismos de un mundo de desintegración que caminaba progresivamente hacia la "asunción de la realidad" sin poder asumirla. La realidad de la que daba cuenta la escritora era un telón de fondo escindido de los sucesos individuales que protagonizan la narración:

5 Esos escritores eran Héctor A. Murena, David Viñas, Alberto Rodríguez (h), Juan José Manauta, Antonio Di Benedetto y Beatriz Guido. 
La novelística de Beatriz Guido se agota en una problemática de raíces éticas, permaneciendo como una crítica moral de la decadencia de las clases altas, pero desde el punto de vista de otro sector ideológico de las mismas clases altas [...] Participando de toda la ambigüedad propia del 'compromiso', la novelística de Beatriz Guido acentúa sus vicios abstractos, no pudiendo fusionar casi nunca el hecho histórico y el hecho individual en una única materia novelística. (Realismo y realidad... 100)

De este modo, Portantiero describía a Fin de fiesta en tanto narración propia de un sector social -la burguesía nacional- que se miraba a sí misma, lamentando su incapacidad de conducción. Un lamento que no le alcanzaba ni como compromiso ni como intención valedera de develar una realidad. Fin de fiesta quería llegar a un estado de conciencia, pero se trata de una responsabilidad puramente formal y retórica. Era un intento de romper con la torre de marfil, provocado por el "papel trastornador" que jugó el peronismo, sin embargo, llevaba consigo "el deseo inconsciente de no romper radicalmente las vallas de la cosmovisión burguesa" (104).

Con una perspectiva afín, el crítico y narrador David Viñas también dedicó algunos párrafos a Beatriz Guido en el ya clásico ensayo Literatura argentina y realidad política (1964). Para Viñas Fin de fiesta daba cuenta del papel desenmascarador del peronismo para con las clases tradicionales, pero la denuncia tenía un carácter insuficiente, porque se disipaba en detalles morales y costumbristas de la oligarquía. La novela, según Viñas, no criticaba los valores de esa clase, sino que enjuiciaba a sus hijos por no haber sabido emplearlos. "Hoy, escribir sobre el recuerdo de las infamias de la oligarquía" -subrayaba- "es engrandecerla a través de lo mejor que le queda, de ahí que la simple descripción se convierta en la exaltación que esa clase estimula y agradece" (116-7). La miseria moral de sus protagonistas (los héroes de otras clases, los que actúan, terminan muertos) señala la connivencia del punto de vista del narrador con los estratos que tenían el poder, de manera que "la imagen del mundo que se formula a través de Beatriz Guido es la típica pauta de una rama segundona codiciosa, ágil, sin mayores escrúpulos, 'modernistas' y dispuesta a negociar" (118). Era, pues, una escritura engañosa e ineficaz, que situaba sus límites en la propia clase, y cuyas representaciones se 
colocan "fuera del mundo" por su inmovilidad y su ahistoricidad, aunque pretendieran exhibir una imagen de conexión histórica.

Las apreciaciones de Portantiero y Viñas dialogan directamente, como puede apreciarse, con el fracaso político y cultural al que se asistía entonces entre el encuentro de la modernidad de los proyectos políticos en pugna frente al horizonte revolucionario que se había abierto en 1959 con la Revolución Cubana. Independientemente de este aspecto, Jitrik, Viñas y Portantiero coinciden en el prisma con el que se acercan a una misma obra, evidentemente atractiva para el debate de entonces. Estos núcleos -exigencia de realidad, mímesis, apremio por la intervención política, dimensión social de la representación, rechazo del psicologismo y de lo fantástico, compromiso- dan pautas para pensar en la sintonía de Fin de fiesta con el juego propio del campo intelectual del cierre de la década de 1950.

\section{Pugna con el peronismo: El incendio y las vísperas}

La publicación de la novela El incendio y las vísperas en 1964 significó un verdadero giro en la carrera de Beatriz Guido. Fue un extraordinario éxito de ventas que la consolidó como productora de best sellers y como una reconocida figura pública, a la vez que la apuntaló como una polemista. Poco antes de llegar a las librerías, el libro tuvo publicidad inusitada en diarios y revistas. La editorial Losada anunció que realizaría tres ediciones simultáneas, un acontecimiento fuera de lo común que causó ciertas suspicacias en el ambiente intelectual frente a tal pretensión. El sello estaba al tanto de la muy exitosa novela Los burgueses de Silvina Bullrich (con un perfil similar a Guido, se mantenía en la lista de los más vendidos desde hacía semanas) y esperaba una respuesta semejante con la nueva obra de Guido 6 .

Efectivamente, el libro fue uno de los grandes sucesos editoriales de la década de 1960. Mucho de su éxito tenía que ver con la clara propuesta antiperonista de la narración y con los debates que rápidamente convocó. Lo que en las obras anteriores quedaba en la sugestión, aquí se volvía

6 La revista Primera Plana se burlaba del anuncio de las tres ediciones simultáneas de El incendio y las vísperas, señalando que tal cantidad "configuraría un fenómeno editorial jamás acaecido en Argentina ni en ninguna parte del mundo", asegurando que el anuncio tenía bastante de truco publicitario (1964, p. 36). 
nítido. La figura central de la novela es la familia Pradere, dueña de una residencia en un barrio exclusivo de Buenos Aires y extensísimos campos en la pampa. En otras palabras, la tipificación (y en ocasiones, la parodia) del patriciado argentino, una figura social señalada particularmente por los discursos de la izquierda latinoamericana durante estos años. En la narración, que se desarrolla entre 1952 y 1953, los Pradere viven el permanente asedio del gobierno peronista; la más importante de esas amenazas es la expropiación de la inmensa estancia para convertirla en un parque público ${ }^{7}$. Para evitar cederla, Alejandro Pradere, cabeza de la familia, claudica y acepta un cargo diplomático en Montevideo, tarea que incluye la vigilancia de los exiliados argentinos en Uruguay. En el medio, los hermanos Inés y José Luis Pradere se alían a un militante anarquista en llevar a cabo un atentado, pero el joven termina secuestrado, torturado y, finalmente, castrado. El episodio que cierra la novela es el incendio del Jockey Club de Buenos Aires, templo tradicional de la sociabilidad oligárquica de Buenos Aires. El edificio es incendiado por la muchedumbre y el propio Alejandro Pradere intenta salvar una estatua de las llamas; poco después se suicida ${ }^{8}$. La ficción colocaba al peronismo y al mismo Perón bajo la imagen de la destrucción y la perversidad -en un fragmento, el mismo presidente parece violar al militante opositor- frente a la alta burguesía, cuya mayor culpa parecía radicar en la claudicación y en su falta de capacidad de conducción social. Con esta construcción del peronismo, El incendio y las vísperas se inscribía en una línea antinacionalista y liberal de la literatura argentina cuyos antecedentes más nítidos eran Amalia de José Mármol (1851) y El matadero de Esteban Echeverría (1871)9.

7 La narración se inicia un 17 de octubre de 1952, cuando los Pradere se levantan a desayunar y se encuentran sin servicio doméstico. 17 de octubre es una fecha emblemática para el movimiento peronista que recuerda la movilización del 17 de octubre de 1945, jornada en que las masas de trabajadores se concentraron en la Plaza de Mayo de Buenos Aires para reclamar el regreso de Juan D. Perón, luego de que fuera desplazado del poder. Durante los gobiernos de Perón (1946-1952 y 1952-1955) ese día se institucionalizó como "Día de la Lealtad", día no laborable en la que los obreros identificados con el movimiento se movilizaban para mostrar su apoyo a su líder. Sobre el peronismo histórico, ver la compilación de Juan Carlos Torre (2002).

8 El Jockey Club de Buenos Aires fue incendiado el 15 de abril de 1953. Este hecho fue motivado por el estallido de dos bombas durante una concentración en Plaza de Mayo que mataron a varias personas. Enfurecidos, grupos de militantes prendieron fuego a varios de los edificios emblemáticos de la oposición: el Jockey Club (cuya destrucción fue total), las sedes de los partidos Radical y Socialista y el Petit Café.

9 Sin entrar en detalles sobre estas dos obras centrales de la literatura argentina, una y otra coincidían en mostrar el régimen de Juan Manuel de Rosas (1835-1852) como una acción autoritaria, intrusiva y perversa. 
Para comprender el interés que motivó este libro de Beatriz Guido, es necesario dar cuenta del cuadro político y cultural en que se publicó. El desplazamiento de Arturo Frondizi por parte de facciones militares en marzo de 1962 implicó la derrota de un ideal de síntesis, así como un triunfo para Perón, que seguía actuando sobre el escenario político durante su exilio. La interrupción institucional señalaba que no era posible gobernar sin su venia y que una buena porción de la población seguía confiando en su regreso. No obstante, el movimiento peronista seguía proscrito y sectores de poder se negaban terminantemente a cualquier expresión que significara populismo. A la vez, una parte de la izquierda empezaba a releer al peronismo (en particular a la figura de Eva Perón) no ya como un régimen autoritario sino como una propedéutica de la Revolución ${ }^{10}$. La discusión estaba abierta. Los liberales (de izquierda o de derecha) reiteraban su rechazo al peronismo; los nacionalistas reconocían su simpatía; la izquierda renovada descubría que su relación con el movimiento no podía ser antagónica si los trabajadores eran peronistas.

El incendio y las vísperas convocó rápidamente críticas en diarios y revistas, a favor y en contra, según la tendencia del medio, y superponiendo la lectura política con la literaria ${ }^{11}$. Las más enconadas fueron, como era de esperarse, aquellas vinculadas con voces peronistas. En verdad, el antagonismo entre Guido y los intelectuales peronistas en el campo de la crítica había comenzado unos años antes en ocasión de la aparición de la premiada novela La casa del ángel (1955). El semanario De Frente, dirigido por John William Cooke (quien durante los años 1960 sería el nexo entre Perón y la izquierda) daba cuenta del rechazo de la literatura de Guido. En un breve artículo crítico, la revista de Cooke apuntaba, entre otras cosas, a que en la novela "lo arbitrario, lo ilógico y lo falso constituyen características esenciales de este libro" (30), a la que calificaba de "pequeña, cuidada y falsamente perversa novela burguesa" (ibíd.).

10 Dentro de esta línea de relectura es ejemplar el ensayo de Juan José Sebreli Eva Perón, ¿aventurera o militante? (1966).

11 La revista Primera Plana, que tuvo una gran presencia política y cultural en los años 1960, marcaba las faltas de sutileza de la novela, su "condenación en masa del fenómeno peronista por un análisis acrítico de sus conflictos". Sin embargo, remarcó su calidad literaria: "pocas novelas argentinas están mejor narradas que ésta, con un sentido tan perfecto de la economía de las situaciones" (1964, 37-8). 
Dada la repercusión pública de El incendio y las vísperas, el mismo Juan D. Perón, desde su exilio en España, salió al cruce para intervenir en el debate. En una entrevista periodística se refirió a la novela, con sarcasmo y humor, como "el 'Grosso Chico' de la Revolución Libertadora" (cit. en Realismo y realidad... 374) ${ }^{12}$. Las palabras de Perón eran sutiles: por un lado, certificaban la preponderancia del costado político de la obra sobreel literario; por otro, le señalaban a Guido la estrechez de sus construcciones históricas y su acercamiento a los sectores más reaccionarios.

Pero fue el agudo ensayista Arturo Jauretche quien se encargó de replicar a la novela con mayor saña, atacando sobre los costados literario, político y hasta personal de la narradora. En su exitoso libro El medio pelo (1966), donde criticaba costumbres, gustos y prácticas de la clase media argentina, Jauretche dedicó un capítulo entero a Guido, tachándola como la escritora ejemplar de esa fracción social (el medio pelo): una autora menor, "subproducto de la alfabetización", a la que le dedicaba esas páginas sólo "por el interés del disector frente a la pieza anatómica" (218). Con una argumentación virulenta, Jauretche objetaba a El incendio y las vísperas la falta de exactitud de muchos de los detalles de la novela, conjeturando que Guido era una autora realista -suposición no del todo cierta si se tiene en cuenta la diversidad de registros de sus escritos ${ }^{13 .} \mathrm{La}$ construcción errónea de los hechos que la novela intentaba dar cuenta no eran consecuencia de una simple negligencia sino una señal del medio pelo de Guido: "Es que el 'medio pelo' se tomó en serio esta novela como histórica y estos Pradere como efectivos representantes de una clase que admira, pero que naturalmente repugna la falsa imagen que se da de ella. Una gafe más del 'puntilloso' medio pelo de la autora" (228).

Así, Beatriz Guido se transformaba en "proveedora intelectual" de esa fracción social que la consumía de manera masiva ${ }^{14}$. Se trataba, en

12 Este dato también está referido en la biografía de Elsa Osorio (1991, p. 141). Con la expresión “Grosso Chico", Perón se refería a un popular libro de historia argentina para estudiantes secundarios escrito por Alfredo Grosso. La autodenominada "Revolución Libertadora" fue el golpe de Estado realizado por una alianza de militares nacionalistas y liberales que derrocó a Perón en setiembre de 1955.

13 Las fuentes estéticas y discursivas de Guido pueden rastrearse en el realismo psicológico, realismo social, en ocasiones, y hasta el gótico que hizo reconocible muchos de sus trabajos, principalmente la novela La casa del ángel.

14 "Hay aquí un trabajo meticuloso, destinado a desorientar sobre la personalidad del escritor; de una sofisticación persistente en la transferencia de la personalidad por superposición a un medio extraño. Y hay la misma actitud en el lector que no percibe la falsedad y ridículo, porque pertenece al mismo 'medio pelo', inserto en esa falsedad y ridículo, viviendo una mistificación a base de ingentes sacrificios, corresponde a su ausencia de realismo social y económico" (237) 
la opinión de Jauretche, de una novela "antipopular" que se encontraba desconectada con el "país real". Argumento que apuntaba hacia una discusión central en la literatura de esta época. Guido, estaba señalando el ensayista, no se inscribe en ningún realismo sino en una mímica comercial y definidamente burguesa de los tópicos culturales de estos años.

Finalmente, Jauretche la asaltaba en el terreno familiar, señalando en la conocida dedicatoria de El incendio y las vísperas ("A mi padre, que murió por delicadeza" [1985: 7]), la matriz de los movimientos engañosos de su clase: Ángel Guido, comprometido socialista y luego radical, que convino ser funcionario peronista para poder terminar su Monumento a la Bandera en Rosario. Una acción que se objetivaba en el personaje de Alejandro Pradere respecto el gobierno de Perón. Ángel Guido y Pradere habían claudicado por una misma razón: ambos se habían rendido para salvar "la belleza", "la delicadeza" (el Monumento, el Jockey Club). Para Jauretche, esta era una forma de exculpar la acción del padre frente a ese grupo social que la leía y la aplaudía. “iLas cosas que hay que hacer por amor al arte!" (237) apuntaba el ensayista con ironía.

Una crítica tan meticulosa y con tanto encono cimentó la rivalidad de Guido con Jauretche. En la revista Semana ella declaró: “Que sobreviva mucho tiempo Jauretche así siguen vendiendo mis libros" (cit. en Osorio, 1991: 141). En la revista Confirmado agregó:

Estoy eternamente agradecida por la promoción. Por cada libro de él que se vende, se venden tres míos... Lo único que sé de él es que es un hombre que siempre se disfraza de viejo. $\mathrm{Y}$ que tiene tres grandes carcajadas en su vida: Lisandro de la Torre, que se rió de él cuando Jauretche era concejal por el partido conservador; Perón cuando Jauretche quiere compartir la fórmula presidencial y salió Quijano; y Borges cuando Jauretche le llevó un manuscrito. (¿Quién le teme a mis temas? 95)

Con esto contraatacaba al mismo tiempo flancos políticos, personales y literarios. "Yo me deslumbré con los obreros de Perón también, pero una sola vez. El primer 17 de octubre. Me impresionó tanto como un fresco de Siqueiros o Rivera", ilustró otra vez con sarcasmo (Verbitsky 40). Y, juntando rencores, alrededor del dilema peronista: "Odio en 
primer lugar a Perón, por su falta de rigor en las estructuras filosóficas. [También] a Jauretche, a Alfredo Palacios, a Ezequiel Martínez Estrada. Son los grandes traidores de una generación que nos dejó sin maestros" (Ibíd.).

Formada en la tradición socialista y liberal, la presencia del peronismo la descolocaba y a la vez la construía como figura intelectual. Algunos años más tarde, en ocasión de la publicación de su libro de cuentos Los insomnes (1973), Guido volvió a reflexionar sobre el significado de El incendio y las vísperas y sobre su intervención en el debate de los años 1960: “En El incendio le hago juego a la derecha. Tienen razón aquellos que me criticaron. Intenté pintar lo que puede hacer una clase para defender la tierra; se hacen peronistas para que no les parcelen el Parque de la Ancianidad; ahí sí hice política de clase. Critiqué tanto lo de Perón, torturas, etc. que se me fue de las manos, me pudo mi clase" (Los insomnes 12).

Aun así, entendía que Perón (y 1973 sería el año del regreso del líder al país) y todo acercamiento al peronismo por parte del arco político significaba un retroceso político: "Para mí el acercamiento al peronismo no tiene sentido. Cada peronista que he conocido dice: el peronismo salvará al país del socialismo. Eso me deshace" (ibíd).

\section{En la puerta de años 1970: Escándalos y soledades}

Pasaron seis años antes de que Beatriz Guido volviese a editar una novela. Durante ese lapso se sumergió en la teoría estructuralista, muy difundida por aquellos años en Europa. La novela Escándalos y soledades, publicada en 1970, tuvo mucho de experimentación en una estética formal cercana a los planteos teóricos que se enlazaban con esa corriente: fragmentos de textos de numerosos autores, juegos paradigmáticos con palabras, citas libres, fragmentación reiterativa. Una renovación formal que no ocultaba preocupaciones políticas semejantes a las narraciones anteriores.

Por entonces, todo horizonte de la socialdemocracia se había disipado. El país estaba en manos de los militares de postura liberal y autoritaria (en 1966 habían derrocado el gobierno del radical Arturo Illia). La única salida democrática parecía perfilarse en el regreso de Perón al país. A la 
vez el clima político y cultural estaba cada vez más lejos de cualquier mesura republicana: las facciones se habían polarizado firmemente, y más aún, muchos intelectuales se habían plegado al compromiso directo con un cambio político, principalmente con grupos de izquierda y peronistas.

La narración de Escándalos y soledades se sitúa en un viejo caserón del Barrio Sur de Buenos Aires, frente a la antigua Biblioteca Nacional, a mitad del siglo XX. Sin padres (un aspecto significativo), el adolescente Doro Astrada es criado por sus tres hermanos mayores en el relegado y envejecido barrio. Su suspicaz hermano, que tiene raíces en el viejo socialismo, Martín Astrada, intenta lograr un acuerdo con Perón, empresa en que falla porque se adelantan los hombres de Frondizi. En medio, el personaje Galileo Abencerraf, personaje que "casi había nacido con la Biblioteca Nacional" y que encarna la figura de la izquierda ilustrada, inicia un largo viaje para perseguir y vengar al asesino de Trotsky, tarea que también se frustra. A partir de un complejo collage de fragmentos y retazos de textos, las acciones y los personajes de la novela rodean el destino desventurado de la utopía republicana. Con un gesto melancólico y cansado, Guido vuelve a los tópicos de los ideales marchitos de la izquierda argentina y su corta capacidad de convocatoria frente al peronismo. Todo esto, téngase en cuenta, circula en un momento en que la izquierda no puede separarse del imaginario revolucionario y del foquismo cada vez más presentes en toda América Latina.

La revista Los libros, publicación en la que se incorporaban elementos novedosos de análisis literario, como el psicoanálisis, el marxismo althusseriano y elementos de lingüística estructural, publicó la crítica más contundente hacia la novela, firmada por una joven Beatriz Sarlo. Este texto era teóricamente más exhaustivo y sofisticado que los reseñados más arriba. Su análisis del lenguaje, en este sentido no se preocupaba por las correspondencias miméticas o ideológicas en las que insistía Jauretche -Sarlo estaba atenta a la complejidad de la mediación entre el texto y el mundo-. Era, si se quiere, una recepción a la altura intelectual que requería el libro de Guido.

Según Sarlo, Guido reunía textos sin conseguir más que incomprensión y extrañeza: “Beatriz Guido/ Doro Astrada escriben porque no entienden. Entonces juntan, recopilan, coleccionan" (Beatriz Guido... 7). En este sentido, si la escritura no es elección-participación se transforma en escritura-visión, lo que significa un alejamiento, una distancia. Realizado 
este primer acercamiento, la joven ensayista intervenía sobre uno de los pilares de Guido: las ambiciones sociopolíticas de la novela. Guido no era escritora, señalaba Sarlo, sino una cómplice de su clase. Doro es un espía (así se define en la narración). La crítica trasladaba ese rasgo simbólico a la escritora: "Espiar es también una forma de complicidad propia de una clase; equivale a mostrar con inocencia: ellos son así (nosotros, los que nos adscribimos, también)" (ibíd. $)^{15}$. El universo roto de Escándalos falla en la coherencia, quizá por la falta de unidad, y esa marca es la que salva la sinceridad del punto de vista Beatriz Guido: tiene oficio, escribe lo que está permitido, en fin, "la antítesis de lo subversivo" (Ibíd.), término que en ese momento estaba identificado con los valores de la izquierda.

Sarlo veía en Escándalos la condensación económica de la obra de Beatriz Guido. Fin de fiesta, El incendio y las vísperas, Escándalos $y$ soledades, todas ellas cimentadas por "el antiperonismo liberal y burgués, que no entiende bien a su hijo, el frondicismo, y que no puede liberarse de las tilinguerías de clase por las que Jauretche incorporó definitivamente a Beatriz Guido al medio pelo" (ibíd.). En esas novelas se reiteraban dos tipos de personajes: los que actuaban y los que miraban, siendo éstos últimos los que se apropiaban de la acción, a través de la sola contemplación. La historia estaba paralizada frente a la mirada impávida de sus protagonistas, no podía cambiarse, rasgo significativo en el texto de Sarlo y signo de su tiempo: “Tanto Pradere como Adolfo y Doro desean intervenir o intervienen en la historia que miran, pero enseguida renuncian a hacerlo porque están condicionados a no tomar decisiones: las decisiones ya han sido tomadas por su clase. Quizá Beatriz Guido pueda definirlos como aquellos que pasan a segundo plano 'por delicadeza'" (Ibíd.) ${ }^{16}$.

Quien actúa, exponiendo su cuerpo, termina en el fracaso, la muerte o la castración (como Pablo Alcobendas en El incendio y las vísperas); el que observa, se salva del destino trágico (como Doro Astrada en Escándalos y soledades). Un mismo esquema redunda en las tres obras. De allí la coda implícita que daban a entender estas narraciones. Para Beatriz Sarlo

15 La figura del espía en la narrativa de Guido es estudiada por Nora Domínguez en el artículo "Familias literarias: visión adolescente y poder político en la narrativa de Beatriz Guido" (2004).

16 Con la expresión "por delicadeza" Sarlo se refiere a la dedicatoria de Guido en El incendio y las vísperas "A mi padre, que murió por delicadeza". 
los protagonistas de Guido no actuaban: espiaban, acompañaban, se escondían; el reverso de la urgencia activa. Ese actuar era un imperativo para la crítica de Los libros, el apremio por un cambio político y social efectivo, un aspecto del que la literatura de Guido estaba distante.

\section{Conclusiones}

Las siguientes narraciones de Guido (entre otras, las novelas La invitación y Rojo sobre rojo o las colecciones de relatos Apasionados y Los insomnes) mantuvieron su ánimo polémico y cierto éxito, pero no suscitaron los debates que pueden encontrarse alrededor de las novelas de la saga nacional. Su literatura parecía tener vitalidad en el marco de un campo cultural construido sobre la discusión superpuesta de proyectos culturales, sociales y políticos. En efecto, en la década de 1960, la literatura era un espacio poroso en el que la palabra tenía performatividad sobre la construcción política (siguiendo la prédica de Sartre, "mientras el escritor actúe, sobrevivirá" [¿Qué es la literatura? 187]), de allí el papel fundamental que fue adquiriendo el intelectual, figura más completa que el simple escritor que se construiría a lo largo de estos años (Gilman, 2003). La literatura existía mientras incitaba a la discusión, vivía cuando intervenía. Los años posteriores a la caída de Perón generaron en la cultura un terreno simbólico de disputa particularmente fértil donde se polemizaron los intentos democráticos, los límites reaccionarios, el regreso del peronismo y las nuevas expectativas de la izquierda. Las tendencias antiintelectuales y radicalizadas que fueron ganando paulatinamente lugar en el paso hacia la década de 1970 perdieron interés en una apuesta como la de Guido, moderada, socialdemócrata y poco afín al clima revolucionario de estos años.

Como se ha visto, las tres novelas coinciden en convocar aspectos centrales de los debates políticos de cada coyuntura. En el caso de Fin de fiesta, se trata del encuentro del escritor con la realidad y el consecuente compromiso que exigía una nueva perspectiva a la literatura. Con El incendio y las vísperas Guido trae al escenario de los años 1960, las pugnas alrededor de las relecturas del peronismo y sus perspectivas a la luz de la revolución. Finalmente, Escándalos y soledades se apunta en el medio de los debates frente a la posición del intelectual actúa frente al escritor que contempla. 
No es fácil distinguir el costado literario de la saga de Beatriz Guido sin ver su inserción polémica en cada coyuntura. Efectivamente, los años en que su literatura tiene presencia y toma posición son aquellos en los que coloca en el centro del debate, y, en efecto, con el cierre de ese período (con el regreso de Perón en 1973) su figura se opacó. Polemizar y escribir, decir y discutir, tenían una correspondencia para quienes se participaron en aquella construcción cultural. Guido era consciente de esto; alguna vez, respecto de su mayor crítico, Beatriz Guido comentó: "mientras exista Jauretche, yo existo, mientras el condenado mira al verdugo está vivo todavía; cuando deja de verlo, está muerto." (Los insomnes 33).

\section{Bibliografía}

Beatriz Guido. "La casa del ángel”. De Frente 48 (7 de febrero de 1955): 30- 31.

Borges, Jorge L. "L'illusion comique". Sur 237 (noviembre- diciembre de 1955): 9-10.

Domínguez, Nora. "Familias literarias: visión adolescente y poder político en la narrativa de Beatriz Guido". Revista Iberoamericana 206 LXX (2004, enero-marzo): 225235.

Ediciones. Primera Plana 106 (17 de noviembre de 1964): 38.

Gilman, Claudia. Entre la pluma y el fusil. Debates y dilemas del escritor revolucionario en América Latina. Buenos Aires: Siglo XXI, 2003.

Guido, Beatriz. [1958]. Fin de fiesta. Buenos Aires: Losada, 1967.

Guido, Beatriz. Escándalos y soledades. Buenos Aires: Losada, 1970. . Los insomnes. Buenos Aires: Corregidor, 1973. - ¿Quién le [sic.]teme a mis temas? Buenos Aires: Fraterna, 1977. . [1964]. El incendio y las vísperas. Buenos Aires: Losada, 1985. 
James, Daniel (Comp.). Nueva historia argentina. Tomo IX: Violencia, proscripción y autoritarismo (1955- 1976). Buenos Aires: Sudamericana, 2007.

Jauretche, Arturo. El medio pelo en la sociedad argentina (Apuntes para una sociología nacional). Buenos Aires: Peña Lillo, 1966.

Jitrik, Noé. Seis novelistas argentinos de la nueva promoción. Mendoza: Ediciones Biblioteca San Martín, 1959.

Korn, Guillermo (Comp.). El peronismo clásico (1945-1955) Descamisados, gorilas y contreras. Buenos Aires: Paradiso, 2007.

“Las cenizas de la historia”. Primera Plana 1 de diciembre de 1964(1964, 1 de diciembre): 37-38.

Mucci, Cristina. Divina Beatrice. Una biografía de la escritora Beatriz Guido. Buenos Aires: Norma, 2002.

Osorio, Elsa. Beatriz Guido. Mentir la verdad. Buenos Aires: Planeta, 1991.

Portantiero, Juan Carlos. Realismo y realidad en la narrativa argentina. Buenos Aires: Procyon, 1961.

Sarlo, Beatriz. "Beatriz Guido: el simulacro de lo peligroso". Los Libros 14 (diciembre de 1970): 6-7.

Sarlo, Beatriz. La batalla de las ideas (1943-1973). Buenos Aires: Emecé, 2007.

Sartre, Jean Paul. ¿Qué es la literatura? Madrid: Losada, 2003.

Sebreli, Juan José. Eva Perón, ¿aventurera o militante? Buenos Aires: Siglo XX, 1966.

Terán, Oscar. Nuestros años sesentas. La formación de la nueva izquierda intelectual en Argentina 1956-1966. Buenos Aires: Puntosur, 1991.

Torre, Juan C. (Comp.). Nueva historia argentina. Tomo VIII: Los años peronistas (1943- 1955). Barcelona: Sudamericana, 2002.

Verbitsky, Horacio. "Novela, política, cine: una pasión argentina. Entrevista exclusiva a Beatriz Guido". Confirmado 56 (14 de julio de 1966): 38- 41. 
Viñas, David. Literatura argentina y realidad política. Buenos Aires: Jorge Álvarez, 1964.

Zangrandi, Marcos. Familias póstumas. Fuego, literatura y peronismo. Buenos Aires: Godot, 2016. 